\title{
Are Human Resource Management Professionals Generalists or Specialists? A Critique
}

\author{
B. K. Liyanage1, M. A. D. Lakmali ${ }^{2}$ and T. D. Weerasinghe ${ }^{3}$ \\ ${ }^{1,2,3}$ Department of Human Resource Management, Faculty of Commerce and Management Studies \\ University of Kelaniya, Sri Lanka \\ 3tdtmdananjaya@gmail.com
}

\begin{abstract}
Key Words: Generalists,

HRM Professionals,

Specialists, Specialized

Generalists
\end{abstract}

\begin{abstract}
Human Resource Management (HRM) professionals are unique in their job content and the job context. Not like other professionals, they have to work with lives; not with files or systems. However, their role is not clearly defined yet in the extant literature continuing the debate on whether they are specialists or generalists. Hence, bridging that lacuna, the current study critiques the argument of HRM specialists vs. HRM generalists. A narrative content analysis of relevant literature was conducted. Citation analysis and thematic analysis were performed to explore the specific themes being researched in the context. Building on the results of the content analysis, current critique concludes that HRM professionals should be 'specialized generalists' in any industry. To be specialized generalists they have to root in HRM first, and then should diversify their capabilities into other relevant areas of people management.
\end{abstract}

\section{Introduction}

Human Resource Management (HRM) is one of the most important and vital business functions in any business organization. HRM is the efficient and effective utilization of Human Resources in order to achieve goals of an organization (Opatha, 2012). Numerous types of resources are needed to achieve the goals of an organization. Among those, human resource is more significant and unique because of its unique characteristics which we cannot see in other resources. It is the resource which establishes and achieves the goals, objectives, vision and mission of an organization, and make decisions which are implemented at all the levels of an organization to achieve the aforementioned (Clarke, 1998).

HRM professionals are responsible for thousands of duties within a business. They appear in different names and designations in the business context. At the top level, HR Director, Chief Human Resources Officer (CHRO), HR Generalist, General HR Manager, HR Branch Manager, Assistant HR Manager are some of the example designations.
They are mostly involved in decision making and strategy formulation in the respective field. Professionals require a lot of experience along with hard work, passion and dedication to reach at this kind of a higher level post in HRM. Those professionals typically report to the CEO, Chairman or Board of Directors of the business. Most of the time, at the middle level, Senior Executive HR, HR Specialists, HR Executive, Junior Executive HR, HR Administrator designations are visible. The professionals at this level of HRM are responsible to carry out defined HRM duties in a particular area of HRM or a function of HRM. Typically, they overlook a few HRM functions which are specifically assigned for them to do so. Further, they have to take the responsibility of some other functions such as managing the lower level HRM staff, taking care of employee training and development, and managing the payroll. At the third level which is the HRM operations, HR Assistant, HR Analyst, HR Mentor, HR Intern / Trainee are some of the common designations. The professionals at this level perform operational level repetitive HRM tasks. They should have some 
specialization in certain fields of HRM, and work according to the directions of their seniors / superiors (Woodd, 1997).

Today HRM professionals are considered as 'strategic partners' of the business (Foote \& Robinson, 1999; Long \& Wan Ismall, 2012). They have to build up strategic partnerships and appropriate relationships which run cross different functional areas and projects aiming the increase of organizational productivity (Pritchard, 2010). Being 'change agents' is also a strategic role of HRM professionals today. They should the support changes in the organization and leads initiatives to make changes easier for employees. However, professional competencies alone are not sufficient to enable the HRM professionals to be strategic partners and change agents. Business related competencies which is known as 'the business sense' are also important, because those competencies enable HRM professionals to understand how business is unique, thus can create organization specific HRM solutions. 'Administrative expert' is the third role today which HRM professionals have to play in a business. It is a traditional role in Human Resource Management. Modern Human Resource Information Systems (HRIS) and administrative systems which automate the manual administrative works can effectively facilitate this role of HRM professionals today. Finally, 'employee champion' is the core role to be performed by HRM professionals. It is about protecting employees and protecting their interests to ensure that strategic HRM initiatives are well balanced. Based on those roles, whether HRM professionals are generalists or specialists has become still an unending debate (Pritchard, 2010; Long \& Wan Ismall, 2012).

The one who wish to become a HRM specialist or a generalist depends on a number of factors including his or her personal preferences. Company size also a significant determinant (Lawler \& Mohrman, 2000). As an example, in large organizations typically HRM specialists work, whereas in small and medium scale businesses HRM generalists work.
Hence, a smaller company needs HRM generalists who can handle a variety of tasks under the umbrella of HRM. However, for larger companies, they need subject experts; specialists.

Moreover, HRM generalists have a broader range of responsibilities. They have the responsibility of staffing the organization, providing training \& development for employees at all the levels; creating and maintaining a fair and equitable rewards system; managing the diversity; developing policies, procedures and processes appropriately in recruitment, selection, transfers, promotions, performance management; analyzing HR demand and supply; ensuring that the established practices are the best and do not violate the accepted law. On the other hand, HRM specialists are the subject experts who seriously concentrate on a particular area in HRM (Clarke, 1998; Heaton \& Ackah, 2003; Pritchard, 2010).

\section{Objectives}

The debate on whether HRM professionals need to be specialists or generalists is not yet decided clearly in the extant literature. Various scholars have stated various conclusions in literature which are not consistent with each other. Hence, there is a gap in the up to date body of knowledge relating to the level of specialization of HRM professionals, and keeping a proper trade-off between a specialist and a generalist. Therefore, bridging that lacuna up to a significant extent, the objective of the current critique is to arrive at a conclusion providing an answer for the question raised in the title of this critique. Thereby, to suggest a solid way in which business organizations can generate, develop \& retain their HRM professionals.

\section{Methods}

The qualitative content analysis methodology was adopted in the current study. A narrative critique of the relevant findings in the extant literature known to the researchers was conducted. Hence, the secondary data available at the convenience of the 
researchers were collected following the inclusion criteria of 'generalist vs. specialist in HRM'. Further, analyze the data according to the thematic analysis and put into two basic themes; HRM specialists and HRM generalists.

\section{Findings \& Discussion}

A HRM specialist is someone with the expertise in one or few functions of HRM. In larger organizations different specialists take up different roles such as recruiter, job analyst, training \& development specialist and so on. However, in small and medium scale organizations, an HRM professionals perform all the relevant functions of HRM similar to that HR generalists perform. But in fact, HR specialist's job is more routine and has predefined narrow objectives to be achieved.

An advantage of being a HRM specialist is that a person can focus deeply on a few HRM functions that he/she is interested in. However, as a disadvantage form the organizational point of view, HRM specialists are costly because of their expertise knowledge that can only be affordable to larger scale organizations. Such experts have a limited amount of career opportunities, but can demand more than generalists (Opatha, 2012). An individual's serious concentration on a particular area will make him/her a specialist. If a person keeps concentrating on a particular area of HRM in the long run, he will obtain the expertise essential to be a specialist (Pritchard, 2010).

On the other hand, a HRM generalist is someone who possess wider knowledge and capabilities than HRM specialists (Opatha, 2012). Because they have to perform multi-dimensional HRM roles always. HRM generalist can see a broader picture of the entire HRM function, and how it interacts with other functional areas and the operation of the entire business in general. In fact, being a HRM generalist gives a holistic view of HRM. Since HRM generalists are not framed by one or few specialized areas, they can more easily take the advantage of different opportunities. Therefore, they can approach more strategic work in the HRM profession. 'Strategic Vision' of HRM comes with that so called holistic knowledge (Lawler \& Mohrman, 2000; Heaton \& Ackah, 2003; Lang \& Wan Ismall, 2012; Opatha, 2012).

\section{Conclusion \& Implications}

HRM professionals are the individuals within an organization responsible for HRM functions, and also as the mediators between employees and the organization. Basically, the role of a HRM professional is to create, implement, supervise and manage policies, practices, processes $\&$ procedures aim the well-being of the employees. The current paper critiqued the key differences between two distinct routes among HRM professionals; specialist and generalist. HRM specialists are the professionals those who have trained in a few areas of HRM and concerned with perfecting their HRM skills, while generalists possess deep knowledge and aspire to climb the corporate hierarchy as it exists. In fact, these two major routes have divergent goals, interests and needs.

Indeed, HRM professionals have to work with lives; not with files or systems like in other disciplines. Hence, any HRM professional should be peopleoriented in getting things done through people. It not just having a trade-off among two approaches; task orientation and people orientation. Instead, being people oriented is the way in which HRM professionals persuade employees to achieve the targets of the organization. Thus, having considered the aforementioned facts and arguments it could be concluded that HRM professionals should be 'specialized generalists'. For a specialized generalist in HRM, both 'depth and the width' of the capabilities are equally significant. For that, first they should be rooted in HRM, and should diversify their capabilities into other related areas of managing people at work, which in turn enables them to give the 'optimum contribution' to organizational success. 


\section{References}

Clarke, M. (1998). Can Specialist be General Managers? Developing Paradoxical Thinking in Middle Managers. Journal of Management Development, $12(2)$

Foote, D., \& Robinson, I. (1999). The Role of the Human Resource Manager: Strategist or Conscience of the Organization.

Heaton, N., \& Ackah, C. (2003). Changing HR Careers: Implications for Management Education.

Lawler, E. E., \& Mohrman, S. A. (2000). Beyond the Vision: What makes HR Effective?

Long, C. S., \& Wan Ismall, W. (2012). The HR Specialist as an Agent of Change.

Opatha, H. H. D. N. P. (2012). Human Resource Management: Personnel, University of Sri Jayewardenepura, Colombo-Sri Lanka, Author.

Pritchard, K. (2010). Becoming an HR Strategic Partner: Talent of Transition.

Woodd, M. (1997). Human Resource Specialist Guardians of Ethical Conduct? Journal of European Industrial Training. 